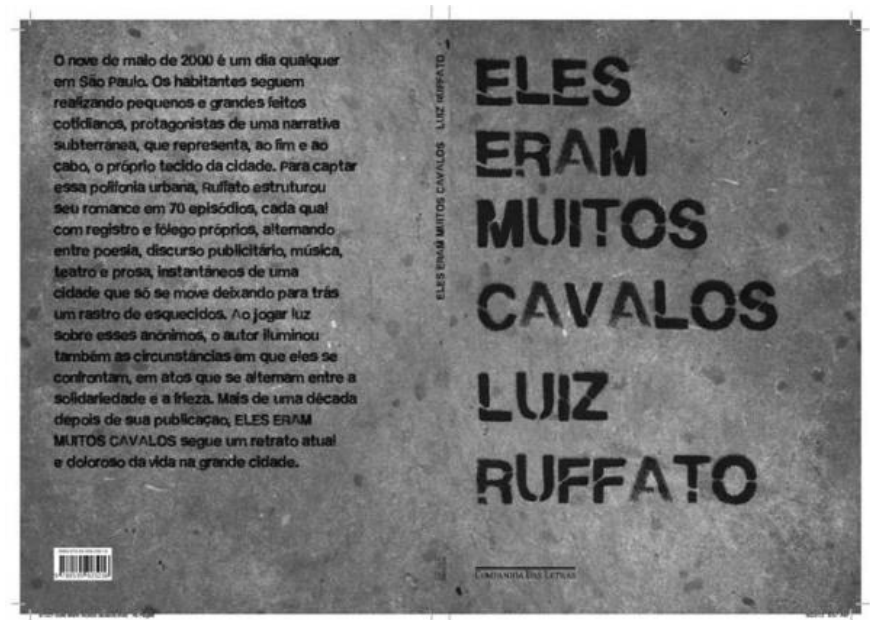

\title{
Vista parcial (das ruas) de São Paulo em Eles eram muitos cavalos de Luiz Ruffato
}

\section{Partial view of the streets of São Paulo in Eles eram muitos cavalos by Luiz Ruffato}

\author{
Camila Galvão de Sousa ${ }^{1}$ \\ ORCID: https://orcid.org/0000-0001-9772-6219 \\ Humberto Fois-Braga ${ }^{2}$ \\ ORCID: https://orcid.org/0000-0002-4179-2564
}

\begin{abstract}
Resumo: A partir dos deslocamentos de personagens pela metrópole de São Paulo no dia 9 de maio de 2000 nos episódios de Eles eram muitos cavalos, de Ruffato, publicado em 2001 e reeditado, após doze anos, pela Companhia das Letras, o artigo objetiva analisar a representação da capital paulista sob o viés da rua. De acordo com a perspectiva de Carlos (2007) e de DaMatta (1997), a rua será considerada não mais como lugar do estar e sim enquanto lugar de passagem e de encontro, de fluidez e de movimento, mas que também admite outros usos, até mesmo no transcurso de um único dia. Dessa forma, percebe-se que há uma fusão entre a degradação urbana presente nas labirínticas ruas de São Paulo, a caracterização de personagens ruffatianos e a estrutura fragmentada das narrativas e do livro como um todo.
\end{abstract}

Palavras-chave: Metrópole; Rua; Degradação; Fragmentação.

Abstract: From the movements of characters throughout the metropolis of São Paulo, on May $9^{\text {th }}, 2000$, in Eles eram muitos cavalos episodes, by Ruffato, published in 2001 and reissued, after twelve years, by Companhia das Letras, the article aims to analyze a representation of the São Paulo capital under the street view. According to the Carlos' (2007) and DaMatta's (1997) perspective, a street will no longer be considered as a place to be but as a place of passage and encounter, of fluidity and movement, but that also admits other uses, even in the course of only a day. Thus, it is clear that a fusion is present between the urban degradation present in the labyrinthine streets of São Paulo, a characterization of Ruffatian characters and a fragmented structure of the narratives and of the book as a whole.

Keywords: Metropolis; Street; Degradation; Fragmentation.

\footnotetext{
${ }^{1}$ Doutoranda do Programa de Pós-graduação em Letras - Estudos Literários da Universidade Federal de Juiz de Fora, UFJF. E-mail: camigalvaos @ gmail.com

${ }^{2}$ Professor do Departamento de Turismo e do Programa de Pós-Graduação em Letras da Universidade Federal de Juiz de Fora. Doutor em Estudos Literários pelo Programa de Pós-Graduação em Letras da UFJF. E-mail: humfois@gmail.com
} 


\section{As experimentações de Ruffato}

Enquanto o eu-lírico de Baudelaire (2012, p. 345) observa uma passante desconhecida, "a rua em torno era um frenético alarido". E, segundo Benjamin (1994), tal multidão parisiense, ainda que não descrita, neutraliza a presença do poeta, tornandose seu refúgio. Trata-se de um amor à primeira vista e, ao mesmo tempo, à última vista, pois, questiona o poeta, "efêmera beldade/ cujos olhos me fazem nascer outra vez,/ não mais hei de te ver senão na eternidade?", e, ainda conclui, "nunca talvez!" (BAUDELAIRE, 2012, p. 345, grifos no original). Em Eles eram muitos cavalos $^{3}$, de 2001, Luiz Ruffato, através da cor cinza que predomina a capa da reedição da Companhia das Letras (2013) e da escolha do título tragicamente poético, metaforiza, assim como Baudelaire, a multidão que, nesse caso, transita pelas ruas de São Paulo no dia 9 de maio de 2000 (terça-feira): aparentemente sem nome, sem pelagem e sem origem tais como os cavalos que pastam nos versos de Cecília Meireles em Romanceiro da Inconfidência $(1953)^{4}$.

Nessas histórias simultâneas e independentes, os narradores de Ruffato, tal como um flâneur, trazem à baila a vida na cidade de outros(as) diversos(as) passantes que dificilmente encantam seus observadores, na vã tentativa de torná-los talvez menos invisíveis no "frenético alarido" das fantasmagóricas ruas de São Paulo. Trata-se de "um bando de trabalhadores pobres, de desempregados, de migrantes fracassados que ignoram a placa de 'não há vagas' e se instalam ali, onde 'não é o seu lugar'”, conforme sintetiza Dalcastagnè (2011, p. 21). Ao leitor, no entanto, não é dado conhecer com segurança tais personagens. É possível conhecer apenas fragmentos de suas vidas estilhaçadas, porque também as narrativas são precariamente interconectadas. Os narradores, em primeira ou terceira pessoa, que aparecem ao longo de Eles eram muitos cavalos, não se apresentam como conselheiros dos possíveis leitores do texto, que, nesse sentido, estão sozinhos na leitura e compreensão das narrativas de suas vidas.

\footnotetext{
${ }^{3}$ Eles eram muitos cavalos foi publicado pela Editora Boitempo em 2001 e reeditado pela Companhia das Letras após doze anos. Esse livro proporcionou a Luiz Ruffato os prêmios "Troféu APCA" e "Prêmio Machado de Assis de Melhor Romance do ano", além de um devido crédito literário que permitiu mais autonomia para suas futuras movimentações no campo brasileiro e maior prestígio na academia com a expansão de sua fortuna crítica, conforme salienta Cerqueira (2016).

${ }^{4}$ A referência à Cecília Meireles acontece de forma explícita, pois os versos do "Romance LXXXIV ou dos Cavalos da Inconfidência", quinta parte do Romanceiro da Inconfidência, aparecem na epígrafe ao livro de Ruffato:

Eles eram muitos cavalos,

mas ninguém mais sabe os seus nomes,

sua pelagem, sua origem...
} 
Ao longo de aproximadamente setenta (fragmentos de) textos numerados e intitulados, destacam-se, além das narrativas, outros gêneros e tipologias textuais (literários ou não) de forma aparentemente aleatória que fazem parte do cotidiano na cidade e podem até mesmo ser facilmente encontrados nas ruas, tais como classificados e anúncios de jornais, numerologia e astrologia, ritual e simpatia, oração, salmo e santinhos, descrição de uma estante de livros, carta manuscrita, conversa telefônica, roteiro teatral, diploma religioso, cardápio e até mesmo a predominância da cor preta em duas páginas no final do livro. Esses diferentes tipos de textos inseridos ao longo do livro, quebram, portanto, a dramaticidade das narrativas e tentam ao menos proporcionar, ainda que criticamente, um momento de alívio e de esperança, tanto para que o leitor prossiga nessa leitura - do texto e da cidade - labiríntica, quanto para que os personagens enfrentem o dia a dia na metrópole que eles mesmos literalmente constroem, como os exemplos a seguir, intitulados, respectivamente, "66" e "Ritual para a terça-feira, Lua em Câncer"'5:

A vibração do número de hoje estimula a realização dos aspectos materiais da vida

(mais dinheiro e prestígio) pode contar com a

ajuda de um amigo influente

promoção

pode receber uma ou herança:

o momento é para ser prático e objetivo (RUFFATO, 2013, p. 19).

Num canto da sala, arme um pequeno altar, usando flores que tiver em casa. No centro, coloque um pratinho com sementes e ervas e componha com um cristal rosa. Acenda uma vela cor-de-rosa e incensos de rosas. Arrume um paninho virgem da cor de sua preferência, abra-o sobre o altar e vá colocando sobre ele as ervas e sementes, oferecendo cada uma

\footnotetext{
${ }^{5}$ Schollhammer (2009), ao realizar um mapeamento da produção ficcional brasileira das últimas décadas, com suas respectivas rupturas e continuidades, destaca a pluralidade de autores e estilos, que perpassam pelas narrativas tradicionais, pelas formas ultracurtas de minicontos, por estruturas complexas e fragmentadas, experiências de linguagem e de estilos, como também por composições híbridas que mesclam o literário e o não literário. O desafio, porém, segundo o autor (2009, p. 14), ainda está em representar "as questões mais vulneráveis do crime, da violência, da corrupção e da miséria". Flora Süssekind (2013, sem paginação), nessa mesma linha de pensamento, denomina de "formas corais" esses novos experimentos reincidentes na cultura brasileira recente de modo geral que utilizam, principalmente, "multiplicidade de vozes, elementos não verbais, e de uma sobreposição de registros e de modos expressivos diversos". Nesse ensaio, a pesquisadora aponta para a difícil classificação crítica e conceitual de tais "coralizações" presentes no campo literário, pois não se encaixam perfeitamente em conceitos já preestabelecidos.
} 
à deusa da Lua, na intenção de encontrar a paz familiar e o amor na relação. Feche o saquinho, amarre-o e use-o com você. Agradeça (RUFFATO, 2013, p. 90).

Através do processo de acumulação de textos diversos, seguido de desestabilização da forma e do olhar do leitor, como define Hossne (2010), há a problematização da própria definição do gênero a que o livro de Ruffato se filia, que é sintomática da relação entre o homem e o mundo, entre o sujeito e a experiência. “Classificar ou não essas obras em categorias é uma dificuldade bem menos importante do que aquela dificuldade mesma que essas obras formalizam ou encenam: a de estabelecer relações, a de conferir sentido, a de ter, senão a totalidade (...) ao menos o impulso de buscá-la", adverte ainda Hossne (2010, p. 166). Luckács (2000, p. 35), em A teoria do romance, de 1916, já constatava a impossibilidade de alcançar tal totalidade, pois a unidade presente nas epopeias de Homero foi substituída, gradativamente, perpassando por Dante, Shakespeare e Cervantes, pela fragmentação do romance, que privilegia a subjetividade consciente do mundo. Novas experiências do sujeito em sociedade exigem novas formas de narrar, complementa Luckács (1965, p. 57) no texto "Narrar ou descrever", já que "todo novo estilo surge como uma necessidade históricosocial da vida e é um produto necessário da evolução social”. Sobre essa questão, o próprio Ruffato também problematiza:

Minha questão é mais da teoria da literatura. A forma clássica do romance foi adequada para resolver problemas do início da Revolução Industrial. Depois, ela foi tendo que se adaptar aos novos tempos, até chegar a Joyce. O instrumento romance, com começo-meio-fim, não faz sentido diante da quantidade de informações de hoje, ficou obsoleto. Minha opção pelo fragmentário foi uma provocação mesmo. Quando eu publiquei o Eles Eram Muitos Cavalos, muitos críticos torceram o nariz e disseram "mas isto não é um romance". Também acho que não é. Mas o que é? Não é um livro de contos. Quero colocar em xeque estas estruturas. Não quero fazer uma reflexão só sobre a realidade política, mas também questionar por meio do conteúdo a forma" (RUFFATO, 2005, sem paginação).

Seria, portanto, Eles eram muitos cavalos, um romance? um livro de (mini)contos? poesia? prosa poética? ou uma mistura de todos esses gêneros? um gênero híbrido? Na verdade, tal definição torna-se menos importante diante do impacto de sua indeterminação formal e da relação entre a forma e o conteúdo, ou melhor, entre a estrutura fragmentada das narrativas e do livro como um todo, a representação do espaço da cidade de São Paulo e a caracterização de personagens. 
Com seus 69 textos curtos que abarcam múltiplas possibilidades enunciativas, o que podemos supor é que, independentemente do gênero que o autor adota, a obra se propõe a ser uma performance palimpséstica da própria cidade de São Paulo: acumulando, em camadas físicas das páginas, aquelas camadas de vidas precárias e que, apesar de quase não percebidas, constituem a cidade; o ato enunciativo se transforma em um arquivo estético das diversas formas de se viver nas cidades modernas. Em seu livro Todas as cidades, a cidade, Renato Cordeiro Gomes (1994) percebe as cidades como um livro de registro que atua como palimpséstico, posto que o seu cotidiano é escrito, reescrito, rasurado diariamente por todos aqueles que a vivem. Por isso, nessa construção de uma narrativa variada em suas enunciações que recuperam fragmentos de um dia comum e banal na grande metrópole brasileira, em Eles eram muitos cavalos, temos o arquivamento literário possível de uma cidade multissensorial, polissêmica e polifônica que traz a constante tensão entre as vidas que se esbarram, se chocam, se amam, se solidarizam, que nascem, trabalham e morrem.

Em outros termos: a obra se torna a possibilidade de inscrever certos traços do palimpsesto urbano de São Paulo em um discurso literário; e, para assim proceder, o autor oferece um tratamento estético aos textos supostamente banais (e.g. diálogos de rua, santinhos distribuídos, cartas, boletins meteorológicos, cartazes e pichações de muro) que se encontram dispersos e sobrepostos pela urbes. É o que veremos a seguir.

\section{As ruas de São Paulo}

Ainda que o cabeçalho com dia, mês, ano e espaço específicos, a previsão do tempo (nublado!) e a hagiologia (a proteção de Santa Catarina de Bolonha aos necessitados), que introduzem Eles eram muitos cavalos, indiquem um certo controle do que será narrado, há, nas páginas subsequentes, uma predominância da descrição sombria, ruidosa e confusa da cidade de São Paulo, que, inclusive, pode ser lida pelo viés da rua, entendida não mais como "lugar do estar" e sim enquanto lugar de encontro e, principalmente, de passagem, de fluidez e de movimento, mas que também admite outros usos, até mesmo no transcurso de apenas um único dia, como definem Ana Fani Alessandri Carlos (2007) e Roberto daMatta (1997).

A rua, portanto, é o lugar da vida, pois é nela que as diferenças e as contradições sociais se revelam de forma concreta na dinâmica do cotidiano, através de gestos, olhares e rostos, como sugere Carlos (2007) e como ilustra o mapa urbano desenhado ao longo das trajetórias de personagens ruffatianas que transitam pelas ruas da cidade, seja usando 
transporte público ou a pé pelas (ausências de) calçadas (irregulares). No contexto da metrópole, ainda segundo Carlos (2007, p. 52), a rua "deixa de ser extensão da casa para se contrapor a ela", visto que:

A metrópole - em visão de grandiosidade aparece em formas exuberantes, ensurdecedora - aparece como o símbolo de um novo mundo, do moderno. Tudo lembra, ou melhor, em tudo há sinais dos tempos modernos marcados pelas formas arquitetônicas grandiosas, nas largas avenidas congestionadas, ruidosas. Espaço instável, em profundo processo de mutação em que no seio da agitação a multidão cada vez mais densa, amorfa, perde sua identidade (CARLOS, 2007, p. 52).

Na narrativa "Vista parcial da cidade" tal desenho urbano torna-se ainda mais evidente e os "relâmpagos" preparam o leitor para a paisagem que será descrita ao anunciar a tempestade que, segundo Benjamin (1987), atinge o anjo de Klee e representa a ilusão que permeia os discursos cristalizados do progresso e da civilidade. Dentro do ônibus lotado, no final da tarde, encontram-se, em destaque, "a velha rente à janela", que não se acostuma ao trânsito, à correria e ao barulho de São Paulo, "a adolescente rente ao corredor", que se sacrifica entre o trabalho meio-expediente e o cursinho pré-vestibular em busca de seus sonhos, e "de pé atrás um homem mão enganchada na alça", que, cansado, após um dia de trabalho, pensa nas prestações atrasadas (RUFFATO, 2013, p. 82-83). O que se passa pelas janelas do ônibus, a cada parada, nas ruas da cidade, conforme descrição a seguir, reflete em tais caracterizações desses personagens que se deslocam por essas ruas e na própria estrutura fragmentada da narrativa:

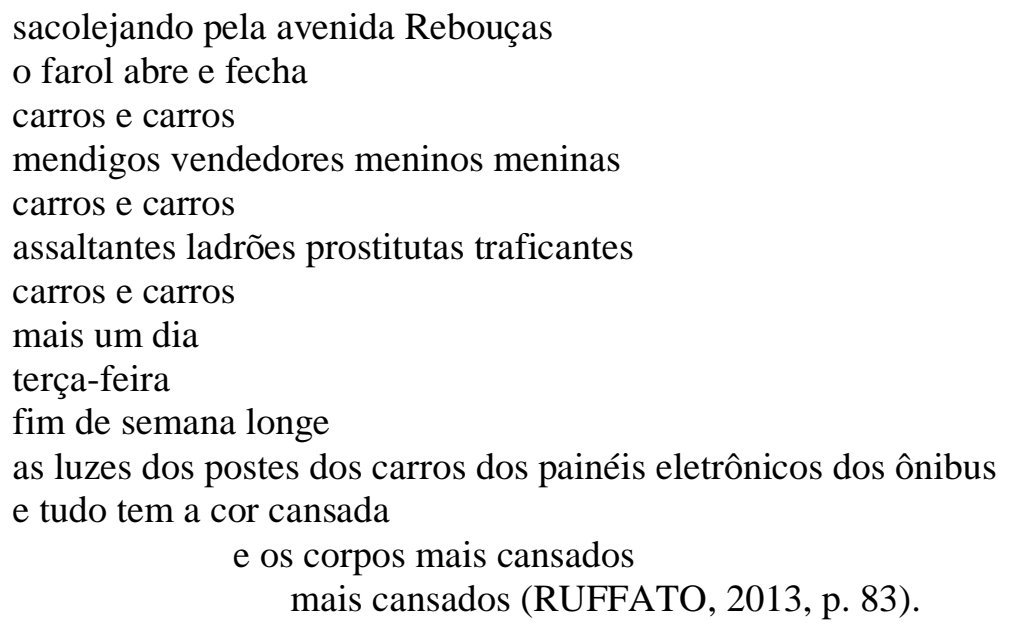

Essas imagens que surgem de forma simultânea e panorâmica como flashes narrativos, cujos sintagmas são divididos pela disposição gráfica do texto sem pontuação, sintetizam a representação da cidade de São Paulo, no início do século XXI, a partir da 
perspectiva "a contrapelo" apresentada por Luiz Ruffato, para usar a expressão de Benjamin (1987). A rua, na metrópole, torna-se avenida. Os carros em movimento prevalecem e as aliterações (repetição do fonema /z/) reforçam os ruídos. Os semáforos, inclusive, impõem o ritmo sincronizado do "pare, atenção e siga" nessa dinâmica urbana, marcada por tendências de homogeneização e normatização da vida, impostas pelas estratégias de poder, e, paradoxalmente, pela permissividade.

A cada parada, a rua, enquanto lugar de passagem daqueles que ao final da tarde retornam para casa, como os passageiros do ônibus, transforma-se: seja pela invasão do mercado e de suas mercadorias, com não apenas a negociação de vendedores no semáforo, mas também prostituição, assalto e tráfico, ou até mesmo para abrigo de "sem-teto" e mendigos, sendo que ambas circunstâncias afastam cada vez mais o fluxo de pessoas. Quase não há indícios de sociabilidade, pois, nas ruas, a multidão neutraliza não só o eulírico de Baudelaire, mas também impõe um comportamento diferenciado de seus frequentadores, impede a relação com o outro e a constituição de grupos afetivos.

Talvez a única "luz no fim do túnel" para aliviar as dores e a "cor cansada" de tudo e de todos seja o fim de semana que ainda não se aproxima, mas seria capaz de resgatar a casa, a família ou ainda a rua enquanto lugar de encontro e de lazer sem os ruídos que predominam a rotina semanal. No entanto, a narrativa termina de forma abrupta, sem ponto final. Essa vista das ruas de São Paulo, embora parcial, é recorrente nas demais narrativas de Eles eram muitos cavalos, como é possível observar também nos próximos três fragmentos de "A espera", "O evangelista" e "Aquela mulher" nessa mesma ordem:

(...) caminha devagar pela rua Sérgio Cardoso (...). Toma o ônibus até a estação Saúde do metrô, baldeia na Sé para a estação República. Da escada-rolante emerge, o edifício Itália funda-se nos seus ombros, a fumaça de carros e caminhões tachos de acarajés coxinhas quibes pastéis, vozes atropelam-se, amalgamam-se, aniquilam-se, em bancas revistas, jornais, livros usados, pulseiras brincos colares gargantilhas anéis, lãs em gorros ponches blusas mantas xales, pontos de ônibus lotados, trombadinhas, engraxates, carrinhos-de-pipoca, doces caseiros, vagabundos, espalhados caídos arrastando-se bêbados mendigos meninos drogados aleijados (RUFFATO, 2013, p. 36).

Na esquina, engraxates da rua Barão de Paranapiacaba, bateia o local revelado em sonho. A seus olhos, caótica, a praça da Sé espicha-se, indolente. Sozinho, perfila-se à boca das escadas-rolantes que esganam as profundezas do metrô. À esquerda, salpicam os degraus da Catedral desempregados, bêbados, mendigos, drogados, meninos cheirando cola, fumando crack, batedores de carteiras, batedores de celular, batedores de cabeça, aposentados, velhacos (RUFFATO, 2013, p. 51). 
aquela mulher que se arrasta espantalha por ruavenidas do Morumbi ignorando ao relento se ratos ou baratas ignorando se chuva ou sol correm pela guia ignorando sapatos tênis havaianas polícia ignorando aquela mulher que se arrasta espantalha por ruavenidas do Morumbi não era assim (RUFFATO, 2013, p. 62).

Primeiro, a visão panorâmica de um desempregado à espera de mais uma falha entrevista de emprego. Depois, a de um missionário na tentativa de uma inútil pregação em busca da salvação divina de si e daqueles que o ignoram. E, por fim, a de uma mãe desesperada e animalizada devido ao sumiço de sua filha. As três situações destacam o caos e o abandono das ruas de São Paulo, como também daqueles que por elas transitam. Essas narrativas também terminam com finais em aberto, representando o indizível... como se, para tais personagens, não houvesse nenhuma solução... ou melhor, se tal solução realmente existe cada qual busca um jeito de adiá-la, como sugere a cena final do livro: "- Porque... porque ainda pode ter alguém lá... E aí... Melhor dormir... Vai... vira pro canto... vira pro canto e dorme... Amanhã... amanhã a gente vê... Amanhã a gente fica sabendo.... Dorme vai.... $) "(R U F F A T O, ~ 2013$, p. 130).

Nessa linha de raciocínio, DaMatta (1997) evidencia, portanto, que as leituras sob a ótica da rua, enquanto categoria sociológica, diferentemente da casa, apresentam discursos mais rígidos com o objetivo de introduzir novos processos sociais, garantindo, assim, o caráter de "decreto, da letra dura da lei, da emoção disciplinada que, por isso mesmo, permite a exclusão, a cassação, o banimento, a condenação" (DAMATTA, 1997, p. 11). Mas, os fundamentos dessa dita ordem, sobre a qual também comentamos anteriormente, podem, sem dúvidas, ser questionados já que, incoerentemente, permitem que, por exemplo, "O crânio", negro e morador da favela, seja abordado cruel e injustamente pelos policiais ou ainda que pessoas, pobres e animalizadas, como em "Chacina n 41 " e "Um índio", morram nas calçadas de São Paulo, de acordo com os fragmentos em destaque:

outro dia o crânio foi barrado na boca da favela

os mílicos estavam fazendo um comando

mandaram ele apresentar os documentos

cacete ele não tem carteira-de-trabalho nem erre-gê cic

a polícia mandou ele deitar no chão sujo

a cara encostada no riozinho de esgoto

colocaram algemas nos punhos e nos calcanhares dele

depois jogaram ele no camburão e sumiram

por essa são paulo tão comprida

encheram ele de porrada torturaram 
o crânio ficou mal logo ele

contra quem ninguém tem bronca (RUFFATO, 2013, p. 89).

(...) debaixo do poste, como que dormissem, três pessoas deitadas, quase amontoadas umas junto às outras. (...) $\mathrm{O}$ que exalava dos corpos era azedume de suor embaralhado ao doceamargo do medo (RUFFATO, 2013, p. 27).

Houve quem tenha visto seus passos cambaleantes empurrarem-no ao encontro da noite áspera, mas só a manhã surpreendeu o índio esticado sob a marquise de uma loja de material-de-construção na avenida Santo Amaro, abraçado a um casco branco vazio, a tudo alheio, a tudo (RUFFATO, 2013, p. 31-32).

Ainda nesse contexto, Teresa Pires do Rio Caldeira (2003, p. 12), na introdução do livro Cidade de muros (2003), reitera uma sintomática transformação ou reorganização do espaço urbano a partir de iniciativas privadas que intensificam ainda mais a desigualdade social e a segregação espacial. As pessoas que vivem à margem da sociedade precisam cada vez mais se conformar "com os restos - as favelas, a periferia, os bairros decadentes, os prédios em ruínas" (DALCASTAGNÈ, 2012, p. 120), como a mãe e seus filhos que, no barraco, (sobre)vivem com os "ratos", que dão título a outra narrativa ruffatiana, e com eles compartilham as mesmas condições precárias de subsistência, tornando-se, de certa forma, todos animais, além dos exemplos já mencionados. Enquanto a classe média (alta) apenas observa “(...) irreconhecível o centro da cidade hordas de camelôs batedores de carteira homens-sanduíche cheiro de urina cheiro de óleo saturado cheiro de (...)" (RUFFATO, 2013, p. 34, grifos do autor), sob a ótica de suas coberturas, de seus carros importados e blindados ou de seus "enclaves fortificados", para usar a expressão de Caldeira.

Nesse processo, "privatização, cercamentos, policiamento de fronteiras e técnicas de distanciamento" substituem os valores estruturantes de "heterogeneidade, acessibilidade e igualdade" (CALDEIRA, 2003, p. 12), que deveriam caracterizar o espaço público, devido ao aumento de experiências de medo e de violência, ao descrédito dos serviços e autoridades públicas e, principalmente, ainda que veladas, às questões étnicas, raciais e de classe. E, aos mais pobres, "o trânsito em determinados lugares e ruas lhes é vetado, como se houvesse placas, visíveis apenas para elas, dizendo "não entre"” (DALCASTAGNÈ, 2012, p. 120). Há, nas ruas de Eles eram muitos cavalos, o encontro entre esses dois mundos apenas no trânsito ou em situações de prostituição, tiroteios, assaltos, sequestro-relâmpago e assassinatos, como ilustram os fragmentos a seguir das narrativas "Negócio" e "Nós poderíamos ter sido grandes amigos", respectivamente: 
O vermelho do farol, observa-o pousado no vidro da janela do carro emparelhado. Assediada, a mulher agarra-se pânica ao volante, entrincheirada: uma velha se oferece buquê de rosas encarnadas; um rapaz martela o pregão de uma caixa de ferramentas; outro embala panos-de-prato, "bordados à mão"; um sujeito sua, nos ombros desfilando uma caixa de copos de água mineral; outro, ensonado bebê ao colo, exige esmolas; rodinho e balde em garras subnutridas disputam para-brisas; adolescentes coxas sorridentes impingem propagandas de imóveis (RUFFATO, 2013, p. 54).

Ele foi vítima de um sequestro-relâmpago.

Os bandidos pegaram ele, parece, na avenida República do Líbano, roubaram os documentos, cheques, cartões de débito e crédito. Depois, numa quebrada escura lá para os lados da represa de Guarapiranga, puseram ele de joelhos, deram um tiro na nuca.

O corpo foi encontrado hoje de manhã.

O carro ainda não (RUFFATO, 2013, p. 42).

Além disso, para finalizar, até mesmo os obstáculos que constantemente tentam impedir a livre circulação de passantes pelas ruas de São Paulo são diferenciados pela classe a que pertencem. Esses obstáculos podem ser ilustrados principalmente através das interrupções das descrições na narrativa "Mãe", marcadas por oscilações gráficas (alteração na fonte, uso de negrito e sublinhado), que impossibilitam a tranquilidade da viagem tão longa e tão esperada de Guaranhuns a São Paulo para rever o filho: ruídos do motor do ônibus, medo, ansiedade e dores físicas: " $A i$, a bexiga, a barriga, as costas, $A i$ !, as escadeiras, Ui!, as pernas, $A i$ !, Ui!, sem posição" (RUFFATO, 2013, p. 19). Em "De cor”, para citar mais um exemplo, três personagens transitam de madrugada, a pé, para o trabalho na transportadora com o objetivo de economizar o pagamento. Ainda que com dificuldades físicas para concluir o trajeto permeado de obstruções naturais e de descaso, eles prosseguem conversando sobre expectativas do futuro: "Vem os três, em fila, pela trilha esticada à margem da rodovia. A escuridão dissolve seus corpos, entrevistos na escassa luz dos faróis dos caminhões, dos ônibus e dos carros que adivinha a madrugada. Caminham, o mato alto e seco roça a perna de suas calças” (RUFFATO, 2013, p. 16). Entretanto, os obstáculos nas ruas da classe média, ainda que sejam as mesmas, não impedem sua efetiva circulação. Na narrativa "A caminho", no trajeto para o aeroporto, as aliterações e onomatopeias garantem a ideia de movimentação do carro e do corpo não claramente identificado. A precariedade do percurso, marcada por "asfalto irregular", "ressaltos", lombadas", "buracos” etc., é amenizada pela indicação de bens de consumo: "couro do volante", "luzes", "música hipnótica" ou ainda o sofisticado "anel" (RUFFATO, 2013, p. 14-15). 
Há, portanto, com base na discussão aqui delineada, uma fusão entre o que personagens de Eles eram muitos cavalos de forma recorrente veem, escutam e sentem, ainda que os exemplos não tenham sido esgotados, que reflete na composição fragmentada interna e externa da narrativa, pois, a partir de colagens, de simultaneidade e também de acumulação, retomando o conceito de Hossne (2010, p. 170), "a temática da degradação urbana também se formaliza numa dialética insólita entre textos/partes e o todo/conjunto" (des)construída, de forma experimental, diante do leitor.

Sobressai-nos, então, uma cidade cansada, em constante tensão entre classes sociais, cujo medo das violências cotidianas impede a solidariedade entre seus habitantes. E, em um tom de desilusão com a urbes, parece-nos que a narrativa termina apontando como que os moradores dessa metrópole operacionalizam estratégias de indiferença em relação ao outro e maneiras de lidar com as suas próprias dores diárias. Em um tom psicanalítico, o sono se insinua como o único local para onde escapar dos problemas - ao menos é o que sugere a penúltima página totalmente preta (metáfora do cair da noite, das luzes que se apagam e dos olhos que se fecham) e o diálogo final entre marido e mulher deitados para dormir: ao ouvir um gemido na porta de casa, ao invés de buscar socorrer, o medo de ser um golpe prevalece à solidariedade e, assim, a mulher termina com a seguinte fala: “Amanhã...amanhã a gente vê...Amanhã a gente fica sabendo... Dorme...vai... (RUFFATO, 2013, p. 130).

Sintomático que a narrativa termine aí, com a porta de casa que não se abre, mantendo-se indiferente aos dramas alheio das ruas, demonstrando a separação entre os de dentro (seguro) e os de fora (perigosos e incapazes de serem lidos - seu sofrimento é real ou fingido?). Em Eles eram muitos cavalos, as fronteiras entre vítimas e algozes tendem a se diluir no final, ao demonstrar que a indiferença - durma para não reagir, durma para fingir que não está vendo - é a atitude de alguns de seus cidadãos que se recolhem dentro de casa e no ambiente mais protegido que pode haver: no quarto, na cama.

\section{Referências}

BAUDELAIRE, Charles. As flores do mal. Trad. Ivan Junqueira. Ed. especial. Rio de Janeiro: Nova Fronteira, 2012.

BENJAMIN, Walter. "Sobre o conceito da História". In.: BENJAMIN, Walter. Magia e técnica, arte e política: ensaios sobre literatura e história da cultura. 7. ed. Trad. Sergio Paulo Rouanet. São Paulo: Brasiliense, 1987. p. 222-232. (Obras escolhidas, 1) 
BENJAMIN, Walter . Charles Baudelaire: um lírico no auge do capitalismo. 2. ed. Trad. José Carlos Martins Barbosa; Hemerson Alves Baptista. São Paulo: Brasiliense, 1994. (Obras escolhidas, 3).

CALDEIRA, Teresa Pires do Rio. Cidade de muros: Crime, segregação e cidadania em São Paulo. 2 ed. São Paulo: 34: Edusp, 2003.

CARLOS, Ana Fani Alessandri. O lugar no/do mundo. São Paulo: FFLCH, 2007.

CERQUEIRA, Rodrigo da Silva. Um escritor excepcional, uma obra de exceção: o Inferno provisório e as movimentações de Luiz Ruffato no campo literário brasileiro. 2016. Tese (Doutorado em Estudos Literários) - Faculdade de Letras, Universidade Federal de Juiz de Fora, Juiz de Fora, 2016. Disponível em: https://repositorio.ufjf.br/jspui/handle/ufjf/3111. Acesso em: 28 set. 2019.

DALCASTAGNÈ, Regina. Pelas margens da cidade: exclusão e silenciamento em Samuel Rawet e Luiz Ruffato. Itinerários, Araraquara, n. 32, p.15-25, jan./jun. 2011. Disponível em: <https://periodicos.fclar.unesp.br/itinerarios/article/view/4573> Acesso em: 01 set. 2019.

DALCASTAGNÈ, Regina. Literatura brasileira contemporânea: um território contestado. Vinhedo: Horizonte, 2012.

DAMATTA, Roberto. Espaço - casa, rua e outro mundo: o caso do Brasil. In: DAMATTA, Roberto. A casa \& a rua: espaço, cidadania, mulher e morte no Brasil. 5. ed. Rio de Janeiro: Rocco, 1997. p. 5-45.

GOMES, Renato Cordeiro. O livro de registro da cidade. In: GOMES, Renato Cordeiro. Todas as Cidades, a Cidade: Literatura e Experiência Urbana. Prefácio de Eneida Maria de Souza. Ed. ampl. Rio de Janeiro: Rocco, 2008. p. 23-40.

HOSSNE, Andrea Saad. Acumulação e desestabilização da forma na narrativa brasileira atual. Teresa, São Paulo, n. 10-11, p. 164-171, 2010. Disponível em: <http://www.revistas.usp.br/ teresa/article/view/116856/114396>. Acesso em: 08 jan. 2020.

LUKÁCS, Georg. A teoria do romance: um ensaio histórico-filosófico sobre as formas da grande épica. Trad. José Marcos Mariani de Macedo. 34. ed. São Paulo: Duas Cidades, 2000.

LUKÁCS, Georg. "Narrar ou descrever". Trad. Giseh Vianna Konder. In.: LUKÁCS, Georg. Ensaios sobre a literatura. Rio de Janeiro: Civilização brasileira, 1965. p. 43-94.

RUFFATO, Luiz. Para Ruffato, "busca pela felicidade apodrece tudo". Entrevista concedida a Cassiano Elek Machado. Folha de São Paulo - ilustrada, São Paulo, mar. 2005. Disponível em: <https://www1.folha.uol.com.br/ fsp/ilustrad/fq1903200507.htm> Acesso em: 10 jan. 2020.

RUFFATO, Luiz. Eles eram muitos cavalos. 11. ed. São Paulo: Companhia das Letras, 2013.

SCHOLLHAMMER, Karl Erik. Ficção brasileira contemporânea. Rio de Janeiro: Civilização brasileira, 2009.

SÜSSEKIND, Flora. "Objetos verbais não identificados: um ensaio de Flora Süssekind". O Globo, 2013. Disponível em: <https://blogs.oglobo.globo.com/prosa/post/objetosverbais-nao-identificados-um-ensaio-de-flora-sussekind-510390.html > Acesso em: 13 jan. 2020.

Data de Recebimento: 31/03/2021

Data de Aprovação: 27/07/2021 


\section{Para citar essa obra:}

SOUSA, Camila Galvão de; FOIS-BRAGA, Humberto. Vista parcial (das ruas) de São Paulo em Eles eram muitos cavalos de Luiz Ruffato. In: RUA [online]. Volume 27, número 2 - p; 375-386 - e-ISSN 2179-9911 - novembro/2021. Consultada no Portal Labeurb - Revista do Laboratório de Estudos Urbanos do Núcleo de Desenvolvimento da Criatividade.

http://www.labeurb.unicamp.br/rua/

Capa: Capa e contracapa do livro Eles eram muitos cavalos de Luiz Ruffato.

Disponível em: https://vermelho.org.br/wp-content/uploads/2019/10/ruffato49445.jpg

Laboratório de Estudos Urbanos - LABEURB

Núcleo de Desenvolvimento da Criatividade - NUDECRI

Universidade Estadual de Campinas - UNICAMP

http://www.labeurb.unicamp.br/

Endereço:

LABEURB - LABORATÓRIO DE ESTUDOS URBANOS

UNICAMP/COCEN / NUDECRI

CAIXA POSTAL 6166

Campinas/SP - Brasil

CEP 13083-892

Fone/ Fax: (19) 3521-7900

Contato: http://www.labeurb.unicamp.br/contato 